\title{
Speed Control of Induction Motor Using New Sliding Mode Control Technique
}

Aamir Hashim Obeid Ahmed Electrical Engineering Department Sudan University of Science and Technology

Khartoum, Sudan

aamirahmed@sustech.edu
Martino O. Ajangnay

Electrical Engineering Department

Sudan University of Science and Technology

Khartoum, Sudan

Ajangnay16@hotmail.com

\author{
Shamboul A. Mohamed \\ Dean College of Engineering \\ Sudan University of Science \\ and Technology \\ Khartoum, Sudan
}

Matthew W. Dunnigan Electrical, Electronics and

Computer Engineering Heriot-Watt University Edinburgh, UK

m.w.dunnigan@hw.ac.uk
Abstract - Induction Motors have been used as the workhorse in the industry for a long time due to its easy build, high robustness, and generally satisfactory efficiency. However, they are significantly more difficult to control than DC motors. One of the problems which might cause unsuccessful attempts for designing a proper controller would be the time varying nature of parameters and variables which might be changed while working with the motion systems. One of the best suggested solutions to solve this problem would be the use of Sliding Mode Control (SMC). This paper presents the design of a new controller for a vector control induction motor drive that employs an outer loop speed controller using SMC. Several tests were performed to evaluate the performance of the new controller method, and two other sliding mode controller techniques. From the comparative simulation results, one can conclude that the new controller law provides high performance dynamic characteristics and is robust with regard to plant parameter variations.

\section{INTRODUCTION}

There is a demand for high performance electric drives capable of accurately executing torque, speed or position demands. This has necessarily led to a growth in the number and sophistication of control methods applied to this problem [1], [2], [3]. Particular attention has been devoted to the induction motor (IM) for reason of cost, size, weight, reliability, simplicity, efficiency and ease of manufacture. The application of advanced control schemes for position or speed control of the IM has been made possible by the increasing power and reducing costs of microprocessors and digital signal processors. Over the past decade, field-oriented control (FOC) or vector control (VC) technique has been widely used in industry for high performance induction motor drive [4], [5], [6], [7], where the knowledge of synchronous angular velocity is often necessary in the phase transformation for achieving the favourable decoupling control. Traditionally, two feedback loops are configured to implement a vector controlled IM drive system. The inner loop is a current regulation loop whereas the outer one is a speed or position regulation loop. Conventionally, the proportional plus integral (PI) controller is simple and very easy to design and implement, and a PI controller is used for both inner and outer loops. However, the performance of PI controller for speed or position regulation degrades under external disturbances and machine parameter variations. Furthermore, the PI controller gain has to be carefully selected in order to obtain a desire response. This makes the use of traditional PI controller a poor choice for industrial variable speed drive applications where higher dynamic control performance with little overshoot and high efficiency is required. The parameter variation issues can be solved by advanced control techniques such as self tuning regulators, and SMC [8], [9], [10].
SMC as a branch of robust control is a powerful technique to control nonlinear systems with uncertainty. The theory of SMC has been developed firstly in Soviet Union by Emelyanov, introduced after by Utkin [11], [12], [13], and more recently studied by several authors [14], [15], [16], [17], [18]. The SMC can offer many good properties, such as insensitivity to parameter variations, external disturbance rejection, and fast dynamic response. These advantages of SMC have been employed in the position and speed control of ac servo systems [1]. The major shortage of SMC is the chattering phenomenon. Several methods have been described in literature to alleviate the chattering. In general, a sliding motion can be divided into two phases: a reaching phase and a sliding phase. The reaching phase is also called non-sliding phase, in which the trajectory approaches the sliding surface from an arbitrary initial position within a finite time. The sliding phase ensures that the trajectory asymptotically move towards the equilibrium point of the sliding surface. When the system states are on the sliding phase, the system response will only depend on the pre-designed sliding surface parameters and is independent of system dynamics. The insensitivity of the controlled system to uncertainties exists in the sliding mode, but not during the reaching phase. Thus, the system dynamic in the reaching phase is still influenced by uncertainties. Therefore, various methods have been suggested to eliminate or lessen the system sensitivity by minimizing or even removing the reaching phase. In [19], high gain feedback was used to minimize the reaching phase. Unfortunately, this may cause sensitivity to unmodelled dynamics and chattering which is undesirable in a physical system. In [20], a time varying sliding surface was proposed to remove the reaching phase by imposing a constraint that initial errors be zero in tracking control.

In this paper, to reduce chattering and accelerate reaching phase a new and simple corrective control signal is proposed depend on the distance between the state error trajectory and sliding surface. To evaluate the performance of the proposed new SMC technique, we provided a series of simulations and a comparative study between the performances of the new proposed controller strategy and two different types of sliding mode controller laws under three different test conditions, nominal inertia, high inertia, and rotor resistance mismatch. Simulation results show that the new sliding mode controller strategy scheme can achieve better performance rotor speed control of a vector controlled induction machine tracking than the two different types of sliding mode controller algorithms in the face of system parameters variation. 


\section{SMC TEChNIQUES}

This section presents the design of new robust sliding mode controller for a vector control IM drive that employs an outer loop rotor speed controller using SMC strategy. Also in this section, two of the most popular sliding mode controller methods are studied and their performance compared with the new proposed controller scheme.

\section{A. New Sliding Mode Controller Technique}

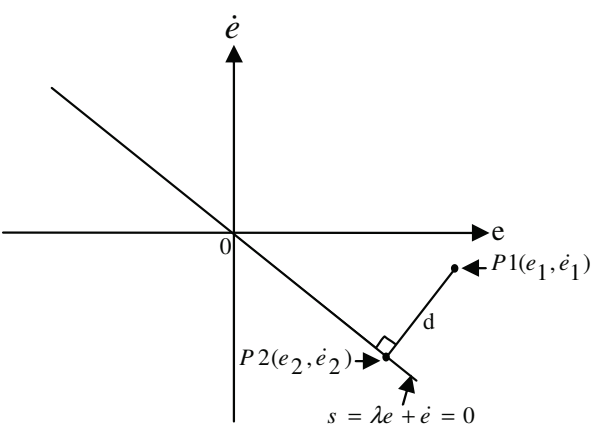

Fig. 1 Derivation of signed distance

From Figure 1 the distance from P1 to the sliding surface (s) is given by the following equation:

$$
d=\left[\left(e_{2}-e_{1}\right)^{2}+\left(\dot{e}_{2}-\dot{e}_{1}\right)^{2}\right]=\frac{\left|\lambda e_{1}+\dot{e}_{1}\right|}{\sqrt{\lambda^{2}+1}}
$$

Without loss of generality (1) can be rewritten as the following equation:

$$
d=\frac{|\lambda e+\dot{e}|}{\sqrt{\lambda^{2}+1}}
$$

The signed distance $\left(\mathrm{d}_{\mathrm{s}}\right)$ is defined for an arbitrary point $\mathrm{P}$ as follows:

$$
d_{s}=\operatorname{sign}(s) \frac{|\lambda e+\dot{e}|}{\sqrt{\lambda^{2}+1}}=\frac{\lambda e+\dot{e}}{\sqrt{\lambda^{2}+1}}=\frac{s}{\sqrt{\lambda^{2}+1}}
$$

From above equation seen that if $s>0$ then $d_{s}>0$, and if $s<0$ then $d_{s}<0$. From this relation the absolute magnitude is proportional to the distance from sliding surface $(\mathrm{s}=0)$, we can conclude that:

$$
u_{c}=-\mathrm{K}_{\mathrm{d}} d_{s}
$$

Where $K_{d}$ positive constant that is defined as weight of distance to improving the control effect. The corrective control action can be determined by distance between the state error trajectory and sliding surface only. It is know that when the state error trajectory is far from the sliding surface $\left|d_{s}\right|$ is large the corrective control gain should be increased to force the state trajectories to approach the sliding surface rapidly and vice verse. Based on the above discussed heuristics, the following rules are proposed.

* If $\left|d_{S}\right|$ is large then $\mathrm{u}_{\mathrm{c}}$ is large.

* If $\left|d_{S}\right|$ is small then $\mathrm{u}_{\mathrm{c}}$ is small.

* If $\left|d_{s}\right|$ is zero then $\mathrm{u}_{\mathrm{c}}$ is zero.

This approach has significant advantage that by applying the large control input when the state error trajectory far from sliding surface, not only the chattering on sliding surface is reduced but also the rate of reaching phase is accelerated. In order to investigate the effectiveness of the new sliding mode controller method, it was applied to position control of induction machine using computer simulation. The control law is proposed as:

$$
\mathrm{u}=\mathrm{u}_{\mathrm{eq}}+u_{d}+u_{c}
$$

Where $u_{e q}, u_{d}$ and $u_{c}$ are control signals for the equivalent, discontinuous, and corrective controls respectively. The $u_{d}$ is defined as:

$u_{\mathrm{d}}=-K \operatorname{sign}(s)$

The sliding surface (s) defined as

$$
s=\lambda \theta_{e}+\dot{\theta}_{e}
$$

Where $\theta_{\mathrm{e}}=$ tracking error $=\theta_{\mathrm{r}}$ (rotor position) $-\theta_{\mathrm{d}}$ (desired rotor position), $\lambda$ is a strictly positive constant that determine the bandwidth of the system, and $\mathrm{K}$ is a positive scalar. For real time implementation the sign term needs to be substituted by a saturation function to attenuate chattering.

$$
u_{\mathrm{d}}=-K \operatorname{sat}\left(\frac{s}{\phi}\right)
$$

where $\phi$ define the width of the boundary layer. Finally the control law is modified to:

$$
\mathrm{u}=\mathrm{u}_{\mathrm{eq}}-K \operatorname{sat}\left(\frac{s}{\phi}\right)+\frac{-K}{\sqrt{\lambda^{2}+1}} s
$$

\section{B. Pseudo Technique}

This control technique is similar to the signum technique except that it addresses the chattering problem. A smoothing factor is introduced in signum function as follows [21]:

$u_{p}=-\mathrm{K}_{\mathrm{p}} \frac{s}{|s|+\delta}$

Where sliding surface (s) has the same definition as (7), $K_{p}$ is a positive scalar, and $\delta$ is a small positive design constant. The signum function effectively becomes a continuous function to avoid the discontinuous effect.

\section{Saturation Technique}

Slotine proposed a technique to change the dynamics near to the sliding surface in order to avoid a real discontinuity and at the same time to preserve the sliding mode properties [20]. This technique introduces a boundary layer $(\phi)$ on both sides of the sliding surface in order to avoid the chattering effect in the control signal. This technique, however, does not ensure the convergence of the state trajectory of the system to the sliding surface, and probably results in the existence of the steady state error. This control algorithm is represented by the following equations.

$u_{\text {sat }}=-\mathrm{K}_{\mathrm{sat}} \operatorname{sat}\left(\frac{s}{\phi}\right)$

Where sliding surface (s) has the same definition as (7). By choosing the control gain $\mathrm{K}_{\text {sat }}$ large enough to overcome the effect of external disturbances (usually set to the maximum value of control effort), the phase trajectory will be forced into the boundary layer (BL) when it is outside. Inside the boundary layer, the control law is continuous thereby eliminating the chattering problem. Therefore the only design 
parameter to choose is the boundary layer width. If too small the saturation control law will resemble the pure discontinuous sliding mode control law approach, if it is too large, the control performance will be influenced.

\section{SLIDING MODE SPEEd CONTROL}

In this section, the three sliding mode controller laws presented previously are compared using the same rotor speed reference command. The speed control goal is to force the rotor speed $\omega_{\mathrm{r}}$ to track the desired rotor speed reference $\omega_{\mathrm{d}}$. For the speed control system, the mechanical equation of an induction motor drive can be represented as:

$$
\dot{\omega}_{\mathrm{r}}=\frac{1}{J}\left(-B \omega_{r}-T_{L}+T_{e}\right)
$$

Where $\mathbf{J}$ is the moment of inertia, $\mathrm{B}$ is the damping coefficient, $\mathrm{T}_{\mathrm{L}}$ is the torque of external load disturbance, and Te denotes the electromagnetic torque. With the implementation of field oriented control, the electromagnetic torque can be simplified as:

$T_{e}=K_{t} i_{q s e}^{*}=\frac{3 P L_{m}^{2}}{2 L_{r}} i_{d s e^{*}}^{*}{ }_{q s e}^{*}$

Where $\mathrm{L}_{m}$ is the magnetizing inductance per phase, $\mathrm{L}_{\mathrm{r}}$ is the rotor inductance per phase referred to stator, $\mathrm{P}$ is the number of pole pairs, $i_{\mathrm{qse}}^{*}$ and $i_{\mathrm{dse}}^{*}$ denote the torque and flux current commands. For all three sliding mode controller techniques, the switching surface is chosen as $\mathrm{s}=\dot{\omega}_{\mathrm{e}}+\lambda \omega_{e}$, where $\omega_{e}=$ tracking speed error $=\omega_{\mathrm{r}}-\omega_{\mathrm{d}} . \quad \lambda$ is a strictly positive constant that determine the bandwidth of the system. The given speed control problem can be treated as a regulator problem, where the desired acceleration is chosen to be zero.

\section{SimULATION RESULTS}

To demonstrate the performance of the new sliding mode controller scheme, some simulation results from the new proposed controller are compared with those from the other tow sliding mode controller laws under three different test conditions. These cases are system at nominal condition, high inertia, and rotor resistance mismatch, respectively. All sliding mode controllers have been implemented in MATLAB/SIMULINK to compare their performance in the rotor speed control case. The simulation is carried out based on the scheme shown in Figure 11 (Appendix). The different sliding mode controller algorithms are compared using the same rotor speed reference command. The results of simulation obtained in this work are for the induction motor of $3 \mathrm{ph}$ and parameters as given in Appendix. The design parameters of the three sliding mode controller methods are shown in Table I.

\section{A. Nominal Condition}

In this section the tracking performance of the new sliding mode controller technique and other two different types sliding mode controller schemes are compared under nominal condition. Figures 2-4 show the rotor speed tracking, rotor speed tracking error, and control effort performance using the three sliding mode controller algorithms. In terms of the speed control trajectories shown in figure 2, all sliding mode controller techniques have a similar performance in term of fast tracking of the desired speed. Figure 3 illustrates that the rotor speed error produced by saturation sliding mode controller is larger than the other two sliding mode controller laws. The maximum rotor speed error for the saturation sliding mode controller is $\pm 0.033 \mathrm{rad} / \mathrm{s}$. the new sliding mode and pseudo controller techniques have shown to have similar amplitudes of maximum rotor speed error. In fact, the peak rotor speed error produced by the new sliding mode controller is smaller than the pseudo sliding mode controller. This means that the new sliding mode controller strategy can track the rotor speed command more accurately than the other two sliding mode controller algorithms. For all sliding mode controller techniques the peak error is below the theoretical tracking precision $\phi / \lambda$ figure of $0.08 \mathrm{rad} / \mathrm{s}$. Figure 4 shows the control effort generated by the different sliding mode controller schemes. The control efforts of the all three sliding mode controller algorithms are similar.

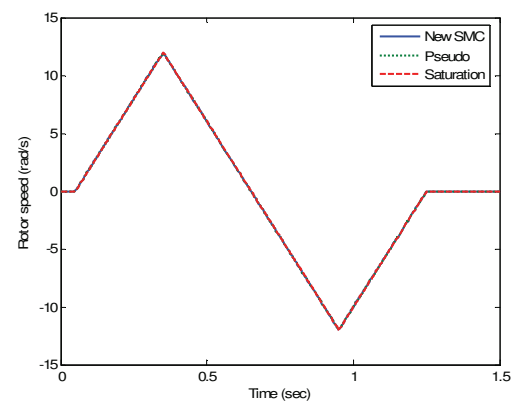

Fig. 2 Rotor speed tracking performance

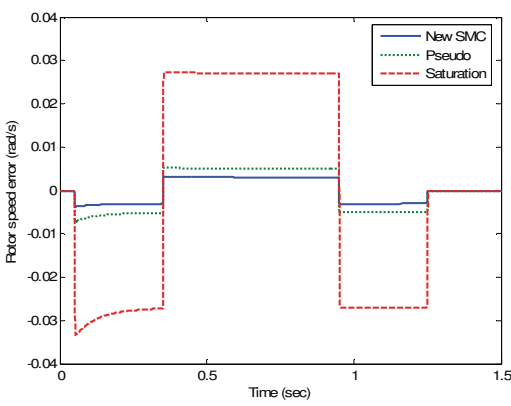

Fig. 3 Rotor speed tracking error

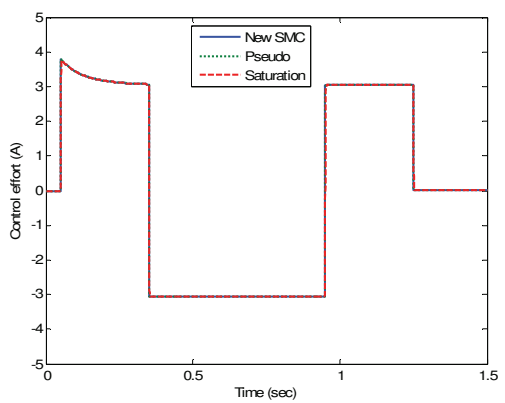

Fig. 4 Control effort

B. Increase the Moment of Inertia

The simulation conditions are the same as in the previous section, but here the moment of inertia $(\mathrm{J})$ of the motor is doubled. Figures 5-6 show the rotor speed tracking, rotor speed error, and control effort using the three sliding mode 
controller laws. The results show that high precision rotor speed tracking still can be attained using the all sliding mode controller techniques, particularly the new sliding mode controller. Figure 5 shows that the three sliding mode controller methods exhibit increased tracking rotor speed errors for a high moment of inertia. Although, the rotor speed error produced by new sliding mode controller is still smaller than the other two sliding mode controller laws. The required control effort signal for all sliding mode controllers is shown in Figure 6. In the moment of inertia case, a higher control effort is demanded to counter this change. From figure 7, it can be seen obviously that the all rotor speed controller methods produced the similar control efforts and the maximum magnitude of the control efforts within $\pm 7.8 \mathrm{~A}$.

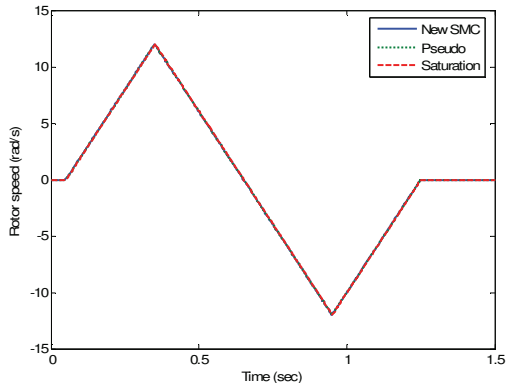

Fig. 5 Rotor speed tracking performance

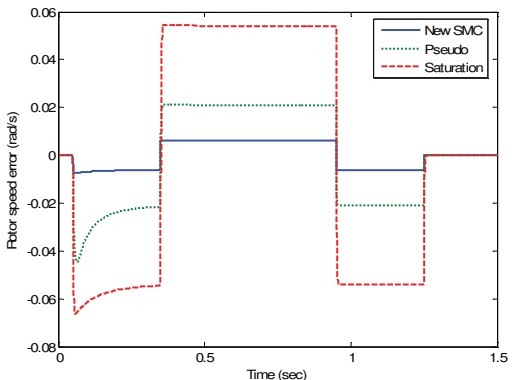

Fig. 6 Rotor speed tracking error

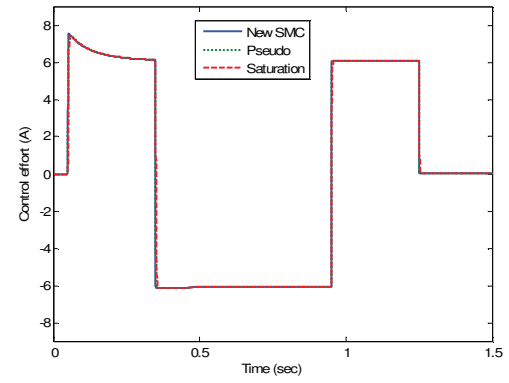

Fig. 7 Control effort

C. Increase the Rotor Resistance

In order to verify the robustness to the change of system parameters, the rotor resistance $\left(\mathrm{R}_{\mathrm{r}}\right)$ of induction motor is increased to $1.75 \Omega$ during the simulation tests. Figures $8-10$ show the simulation results for the three sliding mode controller algorithms under consideration. Figure 9 shows the rotor speed errors generated by the different sliding mode controllers. All speed controller techniques exhibit increased tracking rotor speed errors for the rotor resistance uncertainty.
However, the new sliding mode controller method produces the best rotor speed tracking performance with smaller peak rotor speed error. Figure 10 shows plot of control effort for the different sliding mode controller techniques. All different speed controllers exhibit broadly similar control effort. It can be seen that a higher current signal is required to compensate the rotor resistance mismatch.

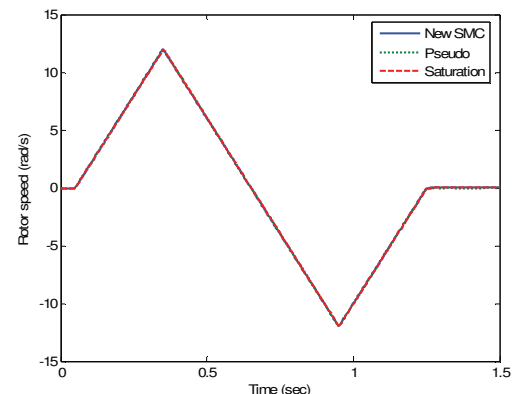

Fig. 8 Rotor speed tracking performance

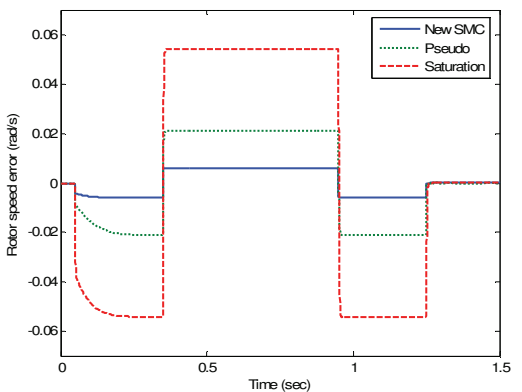

Fig. 9 Rotor speed tracking error

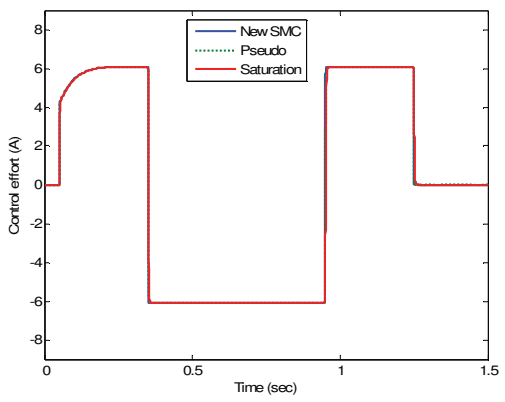

Fig. 10 Control effort

\section{CONCLUSIONS}

In this paper, new technique to reduced chattering for sliding mode control is submitted to design the rotor speed control of induction motor. To validate the performances of the new proposed control law, we provided a series of simulations and a comparative study between the performances of the new proposed sliding mode controller strategy and those of the Pseudo and Saturation sliding mode controller techniques. The sliding mode controller algorithms are capable of high precision rotor speed tracking. From the comparative simulation results, one can conclude that the three sliding mode controller techniques demonstrate nearly the same dynamic behaviour under nominal condition. Also, from the simulation results, it can be seen obviously that the control performance of the new sliding mode controller strategy in 
the rotor speed tracking, robustness to parameter variations is superior to that of the other sliding mode controller techniques.

\section{APPENDIX}

Table I. The design parameters of the three controller

\begin{tabular}{|c|c|c|}
\hline SMC Techniques & Parameters & Values \\
\hline \multirow{3}{*}{ Pseudo } & $\mathrm{K}_{\mathrm{P}}$ & 9 \\
\cline { 2 - 3 } & $\delta$ & 0.1 \\
\cline { 2 - 3 } & $\lambda$ & 10 \\
\hline \multirow{3}{*}{ Saturation } & $\mathrm{K}_{\text {sat }}$ & 9 \\
\cline { 2 - 3 } & $\phi$ & 0.8 \\
\cline { 2 - 3 } & $\lambda$ & 10 \\
\hline \multirow{3}{*}{ New SMC } & $\phi$ & 0.8 \\
\cline { 2 - 3 } & $\lambda$ & 10 \\
\cline { 2 - 3 } & $\mathrm{K}_{\mathrm{d}}$ & 200 \\
\cline { 2 - 3 } & $\mathrm{K}$ & 9 \\
\hline
\end{tabular}

Table II Electrical and mechanical parameters of the IM

\begin{tabular}{|l|c|}
\hline \multicolumn{1}{|c|}{ Parameters } & Values \\
\hline Number of phases & 3 \\
\hline Connection & star \\
\hline Rated power & $2.24 \mathrm{KW}$ \\
\hline Line voltage & $230 \mathrm{~V} \mathrm{rms}$ \\
\hline Line current & $9 \mathrm{~A} \mathrm{rms}$ \\
\hline Rated speed & $1430 \mathrm{rpm}$ \\
\hline Rated torque & $14.96 \mathrm{Nm}$ \\
\hline Rotor resistance, $\mathrm{R}_{\mathrm{r}}$ & $0.72 \Omega$ \\
\hline Stator resistance, $\mathrm{R}_{\mathrm{s}}$ & $0.55 \Omega$ \\
\hline Rotor inductance, $\mathrm{L}_{\mathrm{r}}$ & $0.068 \mathrm{H}$ \\
\hline Stator inductance, $\mathrm{L}_{\mathrm{s}}$ & $0.068 \mathrm{H}$ \\
\hline Magnetising inductance, $\mathrm{L}_{\mathrm{m}}$ & $0.063 \mathrm{H}$ \\
\hline Moment of inertia, $\mathrm{J}$ & $0.05 \mathrm{~kg} . \mathrm{m}^{2}$ \\
\hline Viscous friction coefficient, $\mathrm{B}$ & $0.002 \mathrm{Nms}^{-1}$ \\
\hline Number of pole pairs & 2 \\
\hline
\end{tabular}

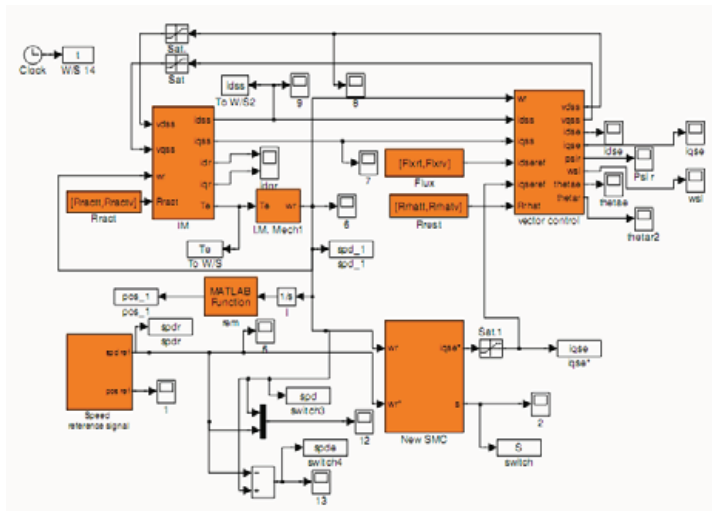

Fig. 11 Simulation system setup

\section{REFERENCES}

[1] S.Wade, M.W.Dunnigan, B.W.Williams, X.Yu, 'Position control of a vector controlled induction machine using slotine's sliding mode control', IEE Proceeding Electronics Power Application, Vol. 145, No.3, pp.231-238, 1998.

[2] V.I.Utkin, 'Sliding mode control design principles and applications to electric drives', IEEE Transactions on Industrial Electronics, Vol.40, No.1, pp. 23-36, February 1993.

[3] P.K.Namdam, P.C.Sen, 'Accessible states based sliding mode control of a variable speed drive system', IEEE Transactions Industry Application, Vol.30, August 1995, pp.373-381.

[4] R.Krishnan, 'Electric motor drives: modelling, analysis, and control', Prentice-Hall, New-Jersey, 2001.

[5] R.J.Wai, K.H.Su, C.Y.Tu, 'Implementation of adaptive enhanced fuzzy sliding mode control for indirect field oriented induction motor drive', IEEE International Conference on Fuzzy Systems, pp.1440-1445, 2003.

[6] W.Leonhard, 'Control of electrical drives', Spring,-Verlag, Berlin, 1996.
[7] M.Dul, 'Novel approach to sliding mode control for field oriented induction motor drive', IEEE International Conference on Industrial Technology, pp. 387-392, 2004.

[8] Z.Beres, P.Vranka, 'Sensorless IFOC of induction motor with current regulators in current reference frame', IEEE Transactions on Industry Applications, Vol.37, pp.1012-1018, July 2001.

[9] R.Krishnan, F.Doran, 'Study of parameter sensitivity in high performance inverter fed induction motor drive systems', IEEE Transactions on Industry Applications, Vol.23, pp.623-635, July/August 1987.

[10] K.Nordin, D Novotny, D.Zinger, 'The influence of motor paramete deviations in feed forward field orientation drive systems', IEEE Transactions on Industry Applications, Vol.21, pp.1009-1015, June 1985

[11] J.J.Slotine, W.Li, 'Applied nonlinear control', Prentice-Hall, Englewood Cliffs, New Jersey, 1991

[12] J.Y.Hung, W.B.Gao, J.C.Hung, 'Variable structure control: A survey', IEEE Transactions Ind Electronic, Vol.40, pp. 2-22, 1993.

[13] V.I.Utkin, 'Sliding mode and their application in Variable structure system", Moscow, 1978.

[14] F.Harashima, H.Hashimto, K.Maruyama, 'Practical robust control of robot arm using variable structure system', Proceedings of the IEEE International Conference on Robotics and Automation, San Francisco, pp.532-538, 1986

[15] H.Hashimto, 'Variable structure system with an invariant trajectory', Power Electronics, Tokyo, Vol.2, 1983

[16] J.J.Slotine, J.A.Coetsee, 'Adaptive sliding controller synthesis for nonlinear systems', International Journal of Control, Vol.43, 1986.

[17] S.Nouri, M.Hamerlain, C.Mira, P.Lopez, 'Variable structure model reference adaptive control using only input and output measurements for two one link manipulators', IEEE SMC, 1993.

[18] K.K.Young, 'Variable structure control for robotics and aerospace applications', Tokyo, 1993.

[19] J.J.Slotine, S.S.Sastry, 'Tracking control of nonlinear system using sliding surfaces with application to robot manipulator', International Journal of Control, Vol.38, No.2, pp. 465-492, 1983.

[20] J.J.Slotine, 'Sliding controller design for nonlinear system', International Journal of Control, Vol.40, No.2, 1984.

[21] K.B.Goh, M.W.Dunnigan, B.W.Williams, 'Speed control of a vector controlled induction machine using sliding mode techniques the presence of nonlinear load dynamics', University of Bath, UK, September 2004 